\title{
Stick then stop before you block
}

M Gallagher, Anaesthetic Registrar, Ninewells Hospital, Dundee J Seeley, Anaesthetic Consultant, Ninewells Hospital, Dundee P Raju, Anaesthetic Consultant, Ninewells Hospital, Dundee S Christie, Anaesthetic Consultant, Ninewells Hospital, Dundee J Bennet, Final year Medical student, University of Dundee

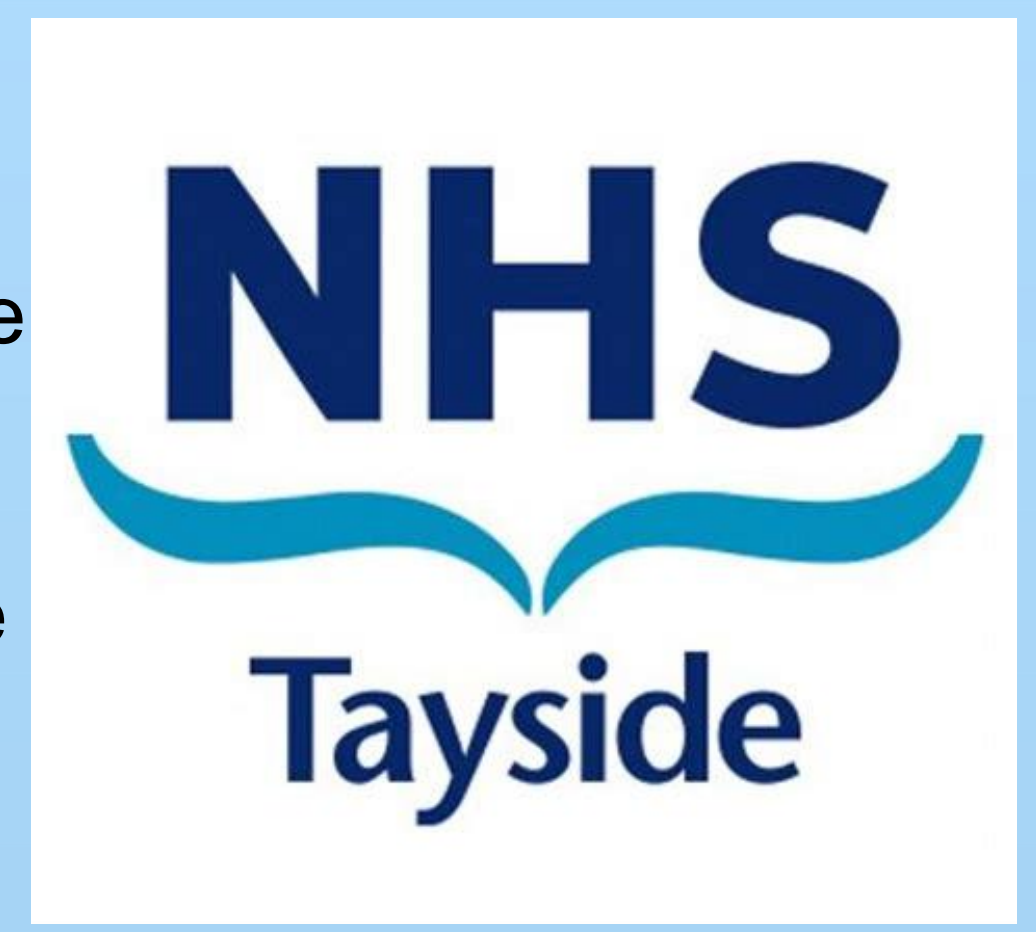

\section{Background:}

The incidence of wrong site block is estimated at 4-7.5 per 10,000 and remains static despite the 'Stop Before you Block' campaign which introduced a final verbal check of site and side prior to needle insertion. This failure is attributed to factors including interruptions, time delays, inadequate documentation and reduced situational awareness.

Pandit et al proposed introducing an action trigger in addition to the SBYB verbal trigger. They advocated a dummy run prior to needle insertion, whilst others suggest block stickers to reinforce the importance of site confirmation at WHO sign-in and add an additional physical action via sticker removal prior to needle to skin. We aimed to introduce this additional safety feature to routine practice within our institute.

\section{Methods:}

Following information dissemination including email, daily safety briefs and theatre walk rounds we introduced our sticker and performed multiple PDSA (Plan Do Study Act) cycles.

Interventions included education sessions, posters, empowering anaesthetic nurses to initiate the stickers, anonymous student observations and feedback forums at each stage.

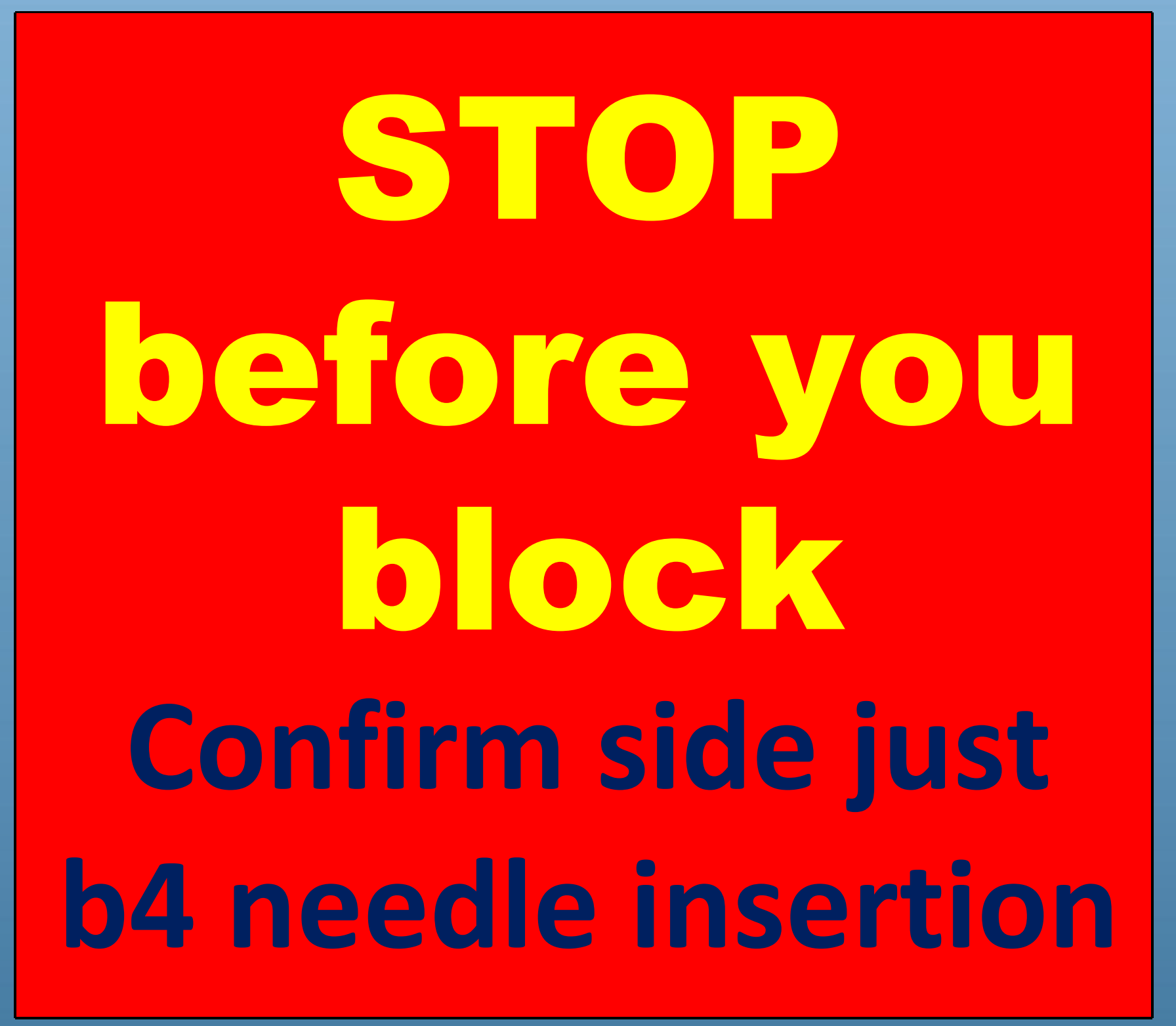

Stop before you block sticker - to be removed prior to needle insertion

\section{Results:}

Compliance of $75 \%$ was achieved in follow up audit, however this dipped to $25 \%$ during direct student observation suggesting disconnect between self-reported use and full compliance. We observed recurring underlying causes of wrong site blocks including interruptions, distraction and target fixation. Reported underlying causes for non-compliance included reluctance to change established 'safe' practice in experienced individuals.

\section{Conclusions:}

Our ongoing challenge therefore is to not only reinforce the process of sticker use, but change behaviors around the time of block insertion to improve safety in regional anaesthesia.

SIGN IN (to be read out loud)

before induction of anaesthesia

\begin{tabular}{|c|c|c|c|}
\hline & & & Yes \\
\hline $\begin{array}{l}\text { Patient confirmed identity \& } \\
\text { procedure, matched with consent } \\
\text { form }\end{array}$ & & & $\square$ \\
\hline Is surgical site/side marked & $\mathbf{N} / \mathbf{A}$ & $\square$ & $\square$ \\
\hline $\begin{array}{l}\text { Regional Block - team confirm } \\
\text { correct block site }\end{array}$ & N/A & $\square$ & $\square$ \\
\hline Any known allergies & No & $\square$ & $\square$ \\
\hline Drug prescription chart checked & & & $\square$ \\
\hline $\begin{array}{l}\text { Confirm anaesthetic plan/concerns } \\
\text { (e.g. airway, blood loss) }\end{array}$ & & & $\square$ \\
\hline Blood available & $\square \mathrm{N}$ & $\square \mathrm{N} / \mathrm{A}$ & $\square$ \\
\hline Patient's pre-operative temperature & & & \\
\hline Anaesthetist : & & & \\
\hline
\end{tabular}

Updated WHO sign in - new emphasis on confirming block side with aim to apply sticker during sign in

1) Pandit JJ, Matthews J, Pandit M. "Mock before you Block": an in-built action check to prevent wrong-side anaesthetic nerve blocks. Anaesthesia 2016.

2) Barrington MJ, Uda Y, Pattullo SJ. Wrong-site regional anaesthesia: review and recommendations for prevention?. Current Opinion in Anaesthesiology. 2015; 28: 670-684

3) Cohen SP, Hayek SM, Datta S et al. Incidence and root cause analysis of wrong site pain management procedures: a multi centre study. Anaesthesiology 2010; 112: 711-718 